\title{
STI Prevalence and Risk Behaviors among Establishment-based and Street-based Sex Workers in Jamaica
}

Jacqueline Duncan ${ }^{\star}$, Sharon Weir, Lovette Byfield, Carol Jones Cooper, Sharlene Jarrett and J Peter Figueroa

Kingston and St. Andrew Health Department, Kingston, Jamaica

"Corresponding author: Jacqueline Duncan, Kingston and St. Andrew Health Department, Kingston, Jamaica, Tel: 8764705633; E-mail: jjjduncan@yahoo.com

Received date: April 28, 2014; Accepted date: June 23, 2014; Published date: July 02, 2014

Copyright: (c) 2014 Duncan J, et al. This is an open-access article distributed under the terms of the Creative Commons Attribution License, which permits unrestricted use, distribution, and reproduction in any medium, provided the original author and source are credited.

\begin{abstract}
Background: Prevalence of sexually transmitted infections (STI) and risk behaviours among street and establishment-based sex workers (SW) were compared.

Method: Between August and November 2008, face to face interviews and testing for sexually transmitted infections (STI) were conducted among Jamaican SW recruited by convenience and snowball sampling.

Results: Forty-five street-based SW (SBSW) and 231 establishment-based SW (EBSW) were recruited. STI Prevalence was: HIV $4.9 \%$, syphilis $6.2 \%$, gonorrhea $12.7 \%$, Chlamydia trachomatis $23.6 \%$, and Trichomonas vaginalis $35.5 \%$. 56.1\% SW had at least one STI and STI prevalence was similar for both groups. Condom use with paying partners was $>90 \%$ but lower with non-paying partners (33.3\% SBSW and 20.8\% EBSW, p = 0.166). Streetbased SW had more partners, initiated sex at an earlier age, operated in fewer parishes, and were more likely to have been exposed to prevention interventions. Daily alcohol, marijuana, and ecstasy use were higher among EBSW compared to SBSW (54.6 vs. $24.4 \%, p<0.001 ; 63.2 \%$ vs. $46.7 \%, p=0.029 ; 34.6 \%$ vs. $6.7 \%, p<0.001$, respectively).
\end{abstract}

Conclusion: Prevention programmes targeting key populations such as SW must address the different risk profiles of sub-populations. Inclusion of strategies to address substance use is critical for effective STI prevention among Jamaican SW.

Keywords: HIV; STI; Sex workers; Epidemiology; Risk behaviours; Jamaica

\section{Introduction}

The HIV epidemic in the Caribbean is largely a mixed epidemic, with a mean HIV prevalence of $1 \%$ in the general population but higher prevalence in populations such as men who have sex with men (MSM), female sex workers (SW), and drug users [1-3]. HIV programmes have placed emphasis on interventions that target these populations and, in the face of diminishing resources, scale up of interventions in such key populations is a regional priority.

In Jamaica, HIV prevalence among SW was recorded as 9\% in 2005 [4], confirming that SW form an important risk group. Various factors have been shown to be independently related to sexually transmitted infections (STI) and HIV occurrence among SW including low levels of education, substance use, gender-based violence, and low knowledge of STI [5-7]. This has informed interventions such as peer education, skills building, and empowerment workshops. However, few studies have explored differences in sub-groups in the SW population that may influence implementation of these interventions.

A 2005 survey of Jamaican SW4 suggested that the risk profile of establishment-based SW (EBSW) may differ from street-based SW (SBSW). In this survey, $18 \%$ of SBSW were HIV positive compared to $5 \%$ of EBSW [4]. However, the survey included a small number of EBSW from 1 establishment and provided little insight into this growing sub-group. Li et al. [8] also found that street- and telephonebased female SW in China had significantly higher risk of syphilis infection

Differences in the risk profile of subgroups of SW is important in Jamaica's HIV response as informal entertainment establishments are common place and many employees engage in sex work $[2,9]$.

A post hoc analysis of a 2008 bio-behavioural survey of Jamaican SW was conducted to determine the risk profiles of establishmentbased sex workers (EBSW) and SBSW.

\section{Materials and Method}

A bio-behavioural survey of sex workers (SW) was conducted between August and November 2008. Participants were recruited from venues in 13 of 14 parishes in Jamaica using convenience and snowballing sampling. Venues (bars, massage parlours, clubs, and street corners) for recruitment were identified by outreach workers of non-governmental organizations, SW peer educators, behavior change communication officers of the National HIV/STI Program (NHP), and Ministry of Health staff. Persons were eligible to participate in the study if they were 16 years or older, consented to being interviewed and undergo testing for HIV and other STI and belonged to one of the following groups: 1) staff at bar or club 2) dancer, entertainer or sex worker 3) referred by outreach worker and 4) male sex worker or beach boy. Face to face interviews were conducted using questionnaires, which were a modified version of the behavioural questionnaire used in a 2005 Jamaica SW survey [4]. 
Citation: Duncan J, Weir S, Byfield L, Cooper CJ, Jarrett S, et al. (2014) STI Prevalence and Risk Behaviors among Establishment-based and

Page 2 of 4

Blood was collected for HIV and syphilis testing using the Determine rapid test and SD Bioline test, respectively. All participants received pretest and posttest counseling for HIV testing consistent with international standards. HIV positive samples were sent to the National Public Health Lab for confirmatory testing using Western Blot (New Lab Blot ${ }^{\circledR}$ ) or ELISA (Architect $\mathrm{Ag} / \mathrm{Ab}^{\circledR}$ ) based on national guidelines. Urine was tested for gonorrhea (GC), Chlamydia trachomatis (CT), and Trichomonas vaginalis (TV) using Gen-probe APTIMA Combo [2]. Unique participant numbers were assigned by interviewers to each questionnaire, providing a link to blood and urine samples. Participants who tested positive for a sexually transmitted infection were treated according to national guidelines. HIV positive sex workers were referred to a treatment site and followed up by a contact investigator.

The study was approved by the Ministry of Health's ethical review committee.

\section{Statistical analyses}

Analyses were done using STATA version 10.1. Respondents were included in the analysis if they reported receiving cash for sex within the past 6 months. Respondents were classified by venue of recruitment: establishment-based (included bars, clubs and massage parlours) versus street-based. Comparisons between groups were performed using chi-square for proportions and Student $t$ test for continuous variables. Fisher exact tests were used for tables with sparse data.

\section{Results}

\section{Demographics}

Three hundred and thirty six persons participated in the survey and 276 persons (82.0\%) who reported receiving cash for sex within the past 6 months were included in the analysis. Of these 276 persons, five were male ( $98 \%$ female). Persons were recruited from 13 of 14 parishes with greater recruitment from urbanized parishes. The majority of persons were interviewed at nightclubs $(71.8 \%)$, followed by street corners $(11.9 \%)$ and massage parlors $(2.5 \%)$. Two hundred and thirtyone SW were recruited from clubs, massage parlours, and bars while $45 \mathrm{SW}$ were street-based. Both groups were similar in age, educational and relationship status (Table 1).

\begin{tabular}{|l|l|l|l|}
\hline & $\begin{array}{l}\text { Establishment- } \\
\text { based SW } \\
(\mathbf{N}=\mathbf{2 3 1})\end{array}$ & $\begin{array}{l}\text { Street- } \\
\text { based SW } \\
(\mathbf{N}=\mathbf{4 5})\end{array}$ & $\begin{array}{l}\mathbf{p} \\
\text { value }\end{array}$ \\
\hline Mean age & $26 \pm 6$ & $31 \pm 9$ & \\
\hline Education & & & 1.000 \\
\hline Primary School & 6.5 & 4.4 & \\
\hline Secondary/high School & 93.5 & 95.6 & \\
\hline Married/Living with main partner & 28.6 & 15.6 & 0.095 \\
\hline $\begin{array}{l}\text { Mean Age at first sex for cash } \\
\text { (years) }\end{array}$ & & & 0.032 \\
\hline$<16$ & 12.1 & 16.3 & \\
\hline $17-18$ & 20.2 & 20.9 & \\
\hline
\end{tabular}

\begin{tabular}{|c|c|c|c|}
\hline $19-24$ & 46.2 & 25.6 & \\
\hline$\geq 25$ & 21.1 & 34.9 & \\
\hline $\begin{array}{l}\text { Number of partners in the past } 4 \\
\text { weeks: }\end{array}$ & & & 0.557 \\
\hline $0-4$ & 35.4 & 16.3 & \\
\hline $5-9$ & 22.9 & 30.2 & \\
\hline$\geq 10$ & 40.8 & 53.5 & \\
\hline \multicolumn{4}{|l|}{ Condom Use at last sex with: } \\
\hline New paying partner & 97.4 & 97.8 & 0.884 \\
\hline Regular paying partner & 90.0 & 93.3 & 1.000 \\
\hline Main (Non -paying) partner & 20.8 & 33.3 & 0.166 \\
\hline \multicolumn{4}{|l|}{ Social Vulnerability } \\
\hline Slept outdoor & 19.9 & 17.8 & 0.839 \\
\hline History of being raped & 22.1 & 17.8 & 0.691 \\
\hline \multicolumn{4}{|l|}{ Substance use } \\
\hline Daily alcohol & 54.6 & 24.4 & $<0.001$ \\
\hline Injection drug & 0.0 & 2.2 & 0.163 \\
\hline Crack/cocaine & 0.43 & 0.0 & 1.000 \\
\hline Marijuana & 63.2 & 46.7 & 0.029 \\
\hline Ecstasy & 34.6 & 6.7 & $<0.001$ \\
\hline $\begin{array}{l}\text { Number of parishes worked in } \\
\text { past } 6 \text { months }\end{array}$ & & & 0.000 \\
\hline 1 parish & 33.3 & 73.3 & \\
\hline$\geq 2$ parishes & 66.7 & 26.7 & \\
\hline \multicolumn{4}{|l|}{ Exposure to interventions } \\
\hline $\begin{array}{l}\text { Attended HIVIAIDS education } \\
\text { session in the past } 6 \text { months }\end{array}$ & 43.7 & 77.8 & $<0.001$ \\
\hline Talked with $\mathrm{MOH}$ outreach worker & 82.3 & 95.6 & 0.024 \\
\hline Had HIV test but not in last year & 18.6 & 6.7 & 0.030 \\
\hline HIV test in the last year & 69.3 & 82.2 & 0.030 \\
\hline Never had HIV test & 12.1 & 8.9 & 0.030 \\
\hline \multicolumn{4}{|l|}{ HIV Prevention knowledge } \\
\hline $\begin{array}{l}\text { Sex with one uninfected partner } \\
\text { can prevent HIV }\end{array}$ & 84.4 & 76.6 & 0.604 \\
\hline $\begin{array}{l}\text { Consistent condom use can } \\
\text { prevent HIV }\end{array}$ & 84.4 & 87.4 & 0.185 \\
\hline Can get HIV from mosquito bites & 4.4 & 13.0 & 0.262 \\
\hline Can get HIV from sharing meal & 8.9 & 10.4 & 0.164 \\
\hline Healthy person can have HIV & 97.8 & 94.4 & 0.823 \\
\hline
\end{tabular}

Table 1: Demographic characteristics and risk profile of Sex Workers by site of recruitment $(\mathrm{N}=276)$ 
Page 3 of 4

\section{Prevalence of Sexually Transmitted Infections (STI)}

The overall HIV prevalence among SW was $4.9 \%$ with similar prevalence recorded in both SBSW and EBSW (4.3\% and 5.0\%, $\mathrm{p}=0.811)$. Prevalence of other STI was similar between both groups and more than half of SBSW and EBSW reported at least one STI (EBSW 55.8\% and SBSW 57.8\%, $\mathrm{p}=0.577$ (Table 2)). The most common STI recorded were Chlamydiatrachomatis (23.6\%) and Trichomonas vaginalis (35.5\%).

\begin{tabular}{|l|l|l|l|l|}
\hline & $\begin{array}{l}\text { Establishment- } \\
\text { based SW } \\
(\%)\end{array}$ & $\begin{array}{l}\text { Street- } \\
\text { based SW } \\
(\%)\end{array}$ & $\begin{array}{l}\text { Total } \\
(\%)\end{array}$ & p value \\
\hline N & 231 & 45 & 276 & \\
\hline HIV & 5.0 & 4.3 & 4.9 & 0.811 \\
\hline Syphilis & 5.5 & 13 & 6.2 & 0.118 \\
\hline $\begin{array}{l}\text { Chlamydia Trachomatis } \\
\text { (CT) }\end{array}$ & 23.4 & 24.4 & 23.6 & 0.877 \\
\hline Gonorrhea & 13.8 & 6.7 & 12.7 & 0.185 \\
\hline Trichomonas Vaginalis & 34.6 & 40.0 & 35.5 & 0.491 \\
\hline Any STI (including HIV) & 55.8 & 57.8 & 56.1 & 0.577 \\
\hline
\end{tabular}

Table 2: Prevalence of HIV and STIs among SW in Jamaica by site of recruitment

\section{Behavioural risk profile}

The mean age at first sex work and the number of partners in the last 4 months tended to be higher among SBSW (Table 1). Among both groups of SW, condom use was high with new paying partners (97.4\% EBSW and 97.8\% SBSW, $\mathrm{p}=0.884$ ) but lower condom use was reported with main/non-paying partners (20.8\% EBSW and 33.3\% SBSW, $\mathrm{p}=0.166$ ).

Substance use was common in this population with 50.0\% SW using alcohol daily, $61.0 \%$ using marijuana and $30.0 \%$ using ecstasy. Alcohol and ecstasy use was significantly higher among EBSW (54.6\% EBSW vs. $24.4 \%$ SBSW, $\mathrm{p}<0.001$ and $34.6 \%$ EBSW vs. $6.7 \%$ SBSW, $\mathrm{p}<0.001$ respectively). SBSW tended to be less mobile with $26.7 \%$ working in more than 1 parish compared to $66.7 \%$ EBSW (Table 1).

\section{Exposure to interventions}

Street based SW had greater exposure to HIV interventions such as participation in HIV/AIDS education session and HIV testing (Table 1). For example, $82.2 \%$ SBSW had an HIV test within the last 12 months compared to $69.3 \%$ EBSW $(\mathrm{p}=0.030)$ and $77.8 \%$ SBSW attended an HIV education session recently compared to $43.7 \%$ EBSW $(\mathrm{p}<0.001)$. However, HIV prevention knowledge did not differ significantly between both groups.

Assessment of HIV prevention knowledge was based on the respondent's ability to identify correctly ways to prevent HIV transmission (i.e. sex with one uninfected partner and consistent condom use) and reject myths (HIV can be transmitted by mosquito bites or sharing a meal).

\section{Discussion}

Sex workers and their partners are key populations that require specific targeted interventions in order to halt and reverse the HIV epidemic [1-3]. This survey suggests that there is high HIV prevalence among Jamaican SW (4.9\%) as well as high prevalence of other STI. However, this was lower than the HIV prevalence recorded in a 2005 survey of Jamaican SW (9\%) [4]. We expected to find a higher prevalence of STI among SBSW compared to EBSW. However, no differences in HIV and STI prevalence were observed between both groups. This is contrary to findings of other surveys $[4,8]$. For example, the 2005 survey of Jamaican SW suggested that HIV prevalence may be higher among SBSW [4]. However, few EBSW were recruited. Similarly, $\mathrm{Li}$ et al. found higher prevalence of gonnorrhea, syphilis and chlamydia among SBSW in Guangdong Province in China compared to establishment-based SW. The finding of similar STI prevalence in EBSW and CBSW in this survey may be a reflection of effective prevention interventions targeting SBSW in Jamaica.

While prevalence of STI was similar for EBSW and SBSW, some important differences in the risk profiles were observed in the 2008 survey. This includes higher levels of mobility and greater substance use, in particular alcohol abuse and ecstasy use, among EBSW. High levels of substance use was documented in the 2005 survey of Jamaican SW with $56.6 \%$ reporting marijuana use and $58.6 \%$ everyday use of alcohol $[4,6]$. The link between intravenous drug or crack/cocaine use and HIV transmission is widely documented and some studies report a link between use of stimulants such as ecstasy with higher HIV prevalence [6,13-16]. This finding is worrisome and suggests that strategies to address substance use in HIV prevention activities targeting SW are important. Many SW surveys and interventions have traditionally focused on SBSW and may not adequately address this risk behavior.

A meta-analysis by Wariki et al. [17] confirms that behavioural interventions are effective in reducing HIV and STI transmission among female sex workers. This study indicates that HIV testing and interaction with Ministry of Health workers were higher among SBSW compared to EBSW. This may be due to the fact that SBSW were the initial targets of interventions for SW. More recent efforts to reach SW in entertainment establishments have been hindered by gatekeepers at clubs and bars. However, the difference in exposure to HIV interventions did not translate to differences in HIV/STI prevalence or comprehensive knowledge about HIV (HIV prevention and rejection of myths). This emphasizes the need to evaluate interventions as well as to better understand and address the underlying social determinants of sexual behavior.

Despite $>90 \%$ condom use with paying partners, low levels of condom use with non-paying partners has been recorded among Jamaican SW in 2 previous surveys (43\% in 2000 and 30\% in 2005) $[4,18]$. While data on HIV prevalence among non-paying partners in Jamaica is not available, high HIV prevalence and risky behaviours among non-paying partners have been reported in other countries [18-21]. Additional efforts are needed to explore and understand this dimension of SW relationships in order to achieve greater behavior change. Prevention messages must emphasize the need for consistent condom use with both paying and non-paying partners. Condom use with non-paying partners should be included among the outcome indicators tracked by HIV prevention programmes.

This survey had several limitations including the sampling methodology and respondent bias. Participants were recruited using 
convenience and snow ball methodology, which may not be representative of the Jamaican SW population. This limits the generalizability of the findings. Unlike the 2005 SW survey, a community informant survey was not conducted to identify new street sites. Failure to recruit from new street sites and sites with uncooperative gatekeepers may have resulted in exclusion of SW with higher risk from the survey. In addition, it is possible that self-reported behaviour on condom use with clients and other high-risk behaviours may have been influenced by social norms and socially desirable responses.

Finally, the analysis did not provide information on male SW which are an important sub-group in the HIV epidemic [10,22]. Little data is available on this population in Jamaica.

\section{Conclusion}

These findings suggest that Jamaican EBSW and SBSW have high prevalence of STI and risky behaviours, which are likely to increase vulnerability. Therefore, both groups should be targeted by prevention programmes. This survey highlights the need for structured approaches to HIV and STI prevention interventions for SW based on a better understanding of the risk profile of sub-groups rather than widespread implementation of generic strategies. Prevention interventions in this population should address substance use in order to achieve desired outcomes.

\section{Acknowledgments}

We thank the staff of the National HIV/STI programme and MEASURE Evaluation for their participation in the execution of the study. Special thanks to the HIV prevention team, which facilitated identification of recruitment sites and study participants.

This study was supported by The Ministry of Health, Jamaica and the National HIV/STI Programme which is a recipient of grants from the Global Fund to fight Aids, Tuberculosis, Malaria and USAID.

\section{References}

1. Joint United Nations Programme on HIV/AIDS (UNAIDS) (2010) Global Report: UNAIDS report on the Global AIDS Epidemic 2010.

2. Figueroa JP, Duncan J, Byfield L, Harvey K, Gebre Y, et al. (2008) A comprehensive response to the HIV/AIDS epidemic in Jamaica: a review of the past 20 years. West Indian Med J 57: 562-576.

3. Ministry of Health, Jamaica (2012) Global AIDS Response Progress Report: Jamaica Country Report. Kingston, Jamaica.

4. Hope Enterprises Limited (2005) Survey of Sex Workers. Kingston, Jamaica 2005.

5. Zhu BY, Bu J, Huang PY, Zhou ZG, Yin YP, et al. (2012) Epidemiology of sexually transmitted infections, HIV, and related high-risk behaviors among female sex workers in Guangxi Autonomous Region, China. Jpn J Infect Dis 65: 75-78.

6. Duncan J, Gebre Y, Grant Y, Wedderburn M, Byfield L, et al. (2010) HIV prevalence and related behaviors among sex workers in Jamaica. Sex Transm Dis 37: 306-310.
7. Lang DL, Salazar LF, DiClemente RJ, Markosyan K (2013) Gender based violence as a risk factor for HIV-associated risk behaviors among female sex workers in Armenia. AIDS Behav 17: 551-558.

8. Li Y, Detels R, Lin P, Fu X, Deng Z, et al. (2012) Difference in risk behaviors and STD prevalence between street-based and establishmentbased FSWs in Guangdong Province, China. AIDS Behav 16: 943-951.

9. Figueroa JP, Weir SS, Byfield L, Hall A, Cummings SM, et al. (2010) The Challenge of promoting safe sex at sites where persons go to meet new sex partners in Jamaica: results of the Kingston PLACE randomized controlled trial. Trop Med Int Health 15: 945-954.

10. Vuylsteke B, Semde G, Sika L, Crucitti T, Ettiegne Traore V, et al. (2012) High prevalence of HIV and sexually transmitted infections among male sex workers in Abidjan, Cote d'Ivoire: need for services tailored to their needs. Sex Transm Infect 88: 288-293.

11. Perla ME, Ghee AE, Sánchez $\mathrm{S}, \mathrm{McClelland} \mathrm{RS}$, Fitzpatrick AL, et al. (2012) Genital Tract Infections, Bacterial Vaginosis, HIV, and Reproductive Health Issues among Lima-Based Clandestine Female Sex Workers. Infect Dis Obstet Gynecol 739624.

12. Altaf A, Agha A, Holte-McKinzie M, Abbas Q, Jafri SB, et al. (2012) Size estimation, HIV prevalence and risk behaviours of female sex workers in Pakistan. J Pak Med Assoc 62: 551-557.

13. Ballester-Arnal R, Salmerón-Sánchez P, Gil-Llario MD, Giménez-Garcia C (2013) The influence of drug consumption on condom use and other aspects related to HIV infection among male sex workers in Spain. AIDS Behav 17: 536-542.

14. Centers for Disease Control and Prevention (CDC) (2012) HIV infection and HIV-associated behaviors among injecting drug users - 20 cities, United States, 2009. MMWR Morb Mortal Wkly Rep 61: 133-138.

15. Boone MR, Cook SH, Wilson P (2013) Substance use and sexual risk behavior in HIV-positive men who have sex with men: an episode-level analysis. AIDS Behav 17: 1883-1887.

16. Carrico AW, Pollack LM, Stall RD, Shade SB, Neilands TB, et al. (2012) Psychological processes and stimulant use among men who have sex with men. Drug Alcohol Depend 123: 79-83.

17. Wariki WM, Ota E, Mori R, Koyanagi A, Hori N, et al. (2012) Behavioral interventions to reduce the transmission of HIV infection among sex workers and their clients in low- and middle-income countries. Cochrane Database Syst Rev 15: CD005272.

18. FHI (2000) HIV/AIDS Behavioural Surveillance Survey Jamaica.

19. Deering KN, Bhattacharjee P, Bradley J, Moses SS, Shannon K, et al. (2011) Condom use within non-commercial partnerships of female sex workers in southern India. BMC Public Health 11: S11.

20. Jain AK, Saggurti N, Mahapatra B, Sebastian MP, Modugu HR, et al. (2011) Relationship between reported prior condom use and current selfperceived risk of acquiring HIV among mobile female sex workers in southern India. BMC Public Health 11 Suppl 6: S5.

21. Couture MC, Soto JC, Akom E, Labbé AC, Joseph G, et al. (2008) Clients of female sex workers in Gonaives and St-Marc, Haiti characteristics, sexually transmitted infection prevalence and risk factors. Sex Transm Dis 35: 849-855.

22. Wong WC, Leung PW, Li CW (2012) HIV behavioural risks and the role of work environment among Chinese male sex workers in Hong Kong. AIDS Care 24: 340-347. 